\title{
Intrathyroidal ectopic thymus in children: a sonographic survey
}

\author{
Adnan Kabaalioğlu, Murat Alp Öztek, Uğur Kesimal, Kağan Çeken, Emel Durmaz, \\ Ali Apaydın
}

Akdeniz University Hospital, Department of Radiology, Antalya, Turkey.

\begin{abstract}
Aims: Intrathyroidal ectopic thymus (IET) is being increasingly reported in the radiology literature. Most of the reports are of individual cases or small series and prevalence and natural course of the pathology is not well known. The purpose of this study is to establish the prevalence of IET in children and report long term follow-up results. Material and methods: In 180 children who were examined by ultrasound (US) for other reasons, 7 patients were indentified with IET. Together with the other seven children who were already under follow-up for IET (diagnosed using US criteria), these 14 patients were followed up with US for 30 months. Size, shape, location, echotexture and internal echoes of the lesions were evaluated. Results: There were 16 lesions in 14 children. The most common appearance was a fusiform hypoechoic lesion, with punctate and linear internal echoes and well-defined but slightly irregular borders located posteriorly in the lower thirds of the thyroid. In follow-up, there were no changes in echotexture, shape or border. In 3 patients, the lesion became slightly smaller, in a 10-year-old boy slightly larger, and in an 11-year old boy the lesion disappeared. In a patient with bilateral lesions, one lesion slightly decreased in size. Conclusions: IET in children may be more common than thought. Its growth reflects that of a normal thymus. Awareness of this entity is important in order not to misdiagnose them, especially as papillary cancer, and to prevent unnecessary interventions.
\end{abstract}

Keywords: ultrasound; thyroid; thymus; pediatric.

\section{Introduction}

Thyroid nodules are less common in children compared with adults and are seen in $0.2-2 \%[1,2]$. However, $20-73 \%$ of nodules found in children are malignant [3]. This makes essential a proper sonographic evaluation of all the nodules and solid knowledge about the differential diagnoses. One possible differential diagnosis that is being increasingly reported in the radiology literature is intrathyroidal ectopic thymus (IET). Most of the reports are of individual cases and prevalence and the natural course of the pathology is not well known.

Received 14.12.2016 Accepted 26.02.2017

Med Ultrason

2017, Vol. 19, No 2, 179-184

Corresponding author: Adnan Kabaalioğlu

Akdeniz Üniversitesi Hastanesi Radyoloji

Anabilim Dalı

Kampüs 07070 Antalya /TURKEY

Phone: +90 2422496457

E-mail: adnank@akdeniz.edu.tr
The purpose of this study is to establish the prevalence of IET in children and report long term follow-up results.

\section{Material and methods}

This was a prospective study, approved by the Institutional Review Board. All investigations were performed after the informed consent was obtained from the parents or the legal guardians of the patients. The study had an initial phase where IET prevalence was determined and then a follow-up phase where children found to have IET in the first phase as well as children already under followup with IET, were included.

\section{Patients}

All pediatric patients referred to our US unit for any indication other than thyroid disease between December 2013 and January 2014 underwent thyroid US $(\mathrm{n}=180)$. Seven children (3.9\%) had findings consistent with IET, as described below. Besides these seven children, there 
were 7 children already under follow-up with IET, diagnosed by A.K. using sonographic criteria described in the literature [4-7]. All 14 children (6 female, 8 male, mean age $6 \pm 3.0$ range 2-12) with a total of 16 lesions were included in the follow-up phase of the study.

\section{US evaluation}

US examinations were performed using a Toshiba Aplio 500 and an Aplio 80 (Toshiba, Japan) with 4-12 $\mathrm{MHz}$ and 5-12 MHz linear-array transducers and Esaote MyLab Class C (eSaote, Italy) with 6-18 MHz lineararray transducer.

US evaluation in the first phase of the study was performed by two radiology residents (M.A.Ö and U.K, 1.5 years of experience at that time) under supervision of a faculty member (A.K, A.A, E.D, K.Ç, all with more than 10 years of experience in thyroid and pediatric US). Seven children who were already under follow-up were diagnosed by A.K. and followed-up by him until the onset of the study. Based on previous reports in the literature, all intrathyroid lesions showing typical features of multiple punctate and linear branching echogenic structures, identical in appearance to normal thymus of the patient in anterior mediastinum were considered IET [4-7]. All patients with suspected IET were further evaluated by A.K, who confirmed or refuted the diagnosis. Images of the patients were stored for future reference and comparison.

Lesions were evaluated by size, location, shape, borders and internal echoes. The location was determined by dividing the gland into 3 pieces craniocaudally and anteroposteriorly. The location of the lesion was then determined accordingly (ie. inferior-posterior, middleanterior). Borders were defined as well-defined when they were easily traced throughout the whole circumference of the lesion and ill-defined when it was difficult to ascertain when the lesion ended and normal thyroid began. Shape was defined as round, ovoid, fusiform or irregular. When a lesion was longer longitudinally than in other dimensions and with tapering ends, it was considered fusiform, if the ends of such a lesion were rounded and not tapering then it was considered ovoid. A lesion not conforming to any of these definitions was defined to be irregular. Internal echoes were punctate, linear or branching.

\section{Follow-up and image comparison}

In the follow-up phase, children were re-evaluated with US at 12, 24, and 30 months. Two patients were lost for follow-up, and 1 patient underwent hemithyroidectomy due to concerns regarding possible thyroid malignancy. Therefore, the study was completed with 11 children with 12 lesions. One patient underwent FNA due to concerns over malignancy. The mean follow-up time was 40 months (range 24-78 months).
Follow-ups were performed by either M.A.Ö or U.K under supervision of the same faculty members. The size of IET was measured in three dimensions and several images in different planes from different levels of the lesion were stored. These images were compared with the previous images concerning the echotexture, internal structure, shape, and borders. In cases where the patients were already under follow-up, three dimensions of the lesion at time of diagnosis were not always available. In such cases, two dimensions in transverse view were used to compare with previous images, at the onset of the follow-up phase, longitudinal dimension was measured and all further evaluations included and compared all three dimensions. Changes in any dimension higher than or equal to $2 \mathrm{~mm}$ between 2 consecutive evaluations, and confirmed by measurements in further follow-up if available, were considered increase or decrease in size. Changes of $1 \mathrm{~mm}$ were considered to be due to variations in the placement of the measurement caliper, unless there were consistent $1 \mathrm{~mm}$ changes in further follow-up.

\section{Results}

Initially 16 IET in 14 children were included. In 4 lesions, the longitudinal dimension at time of initial diagnosis was not available. Average size (APxtransverse) of IET at time of initial diagnosis was $4 \pm 1.7 \times 5 \pm 1.47 \mathrm{~mm}$. Average longitudinal dimension (of 12 lesions) was $9 \pm 3.49$ $\mathrm{mm}$. Two patients ( 1 with bilateral lesions) were lost to follow-up and one patient underwent hemithyroidectomy. The remaining 12 lesions in 11 children were followed-up.

Seven children had lesions on the right, 5 on the left and $2 \mathrm{had}$ one lesion in each lobe. There were no lesions in the superior $1 / 3$ of the gland, whereas 2 were located in the middle 1/3, 2 in the junction of middle and lower thirds, and the remaining 10 in the lower thirds. Simi-

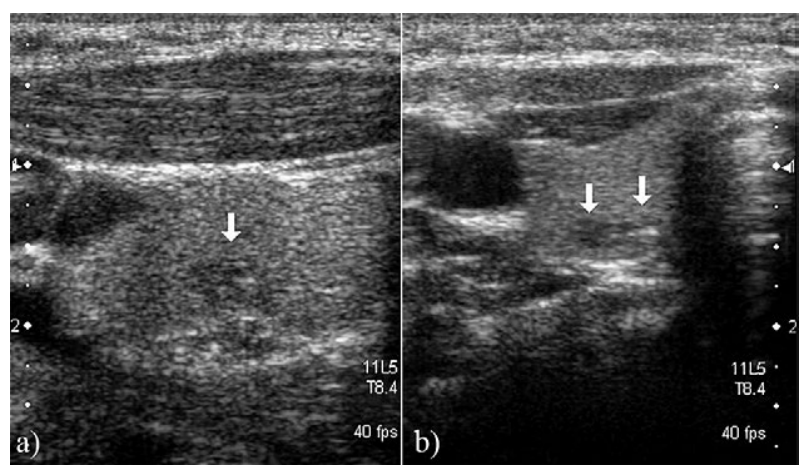

Fig 1. Most common appearance encountered in our study: fusiform in longitudinal view (a) and nodular in transverse view (b), with well defined, but slightly irregular borders and punctate and branching thin linear internal echoes. 


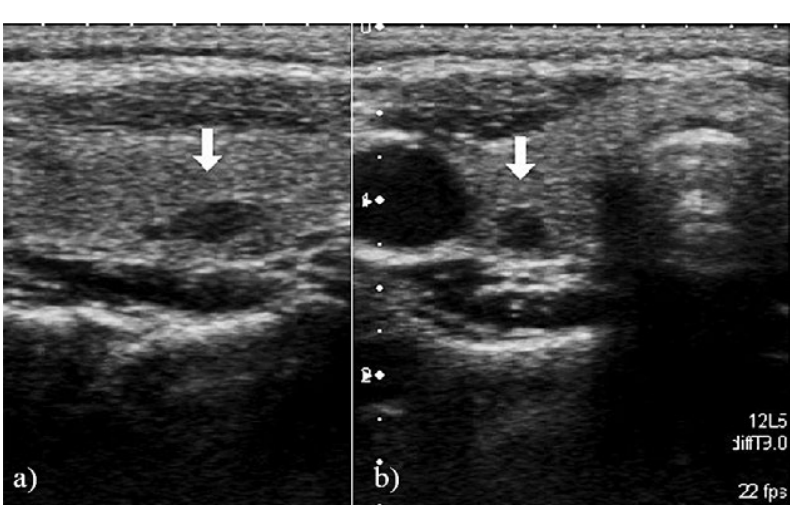

Fig 2. Fusiform hypoechoic IET without internal echoes in (a) longitudinal and (b) transverse views. Thymus of the patient was identical in appearance.

larly, no IET was detected in the anterior $1 / 3$ gland, 4 were detected in the mid-portion of the gland, and 12 in the posterior $1 / 3$.

The most common shape was fusiform in longitudinal view and nodular in transverse view, with well defined, but slightly irregular borders (fig 1). Three lesions were slightly nodular, all others were fusiform. There were no lesions ovoid or irregular in shape or with ill-defined borders. Punctate and branching thin linear internal echoes were present in 14 lesions. Two patients had lesions without internal echoes, and their thymus also was similar in appearance (fig 2). There were no coarse hy-

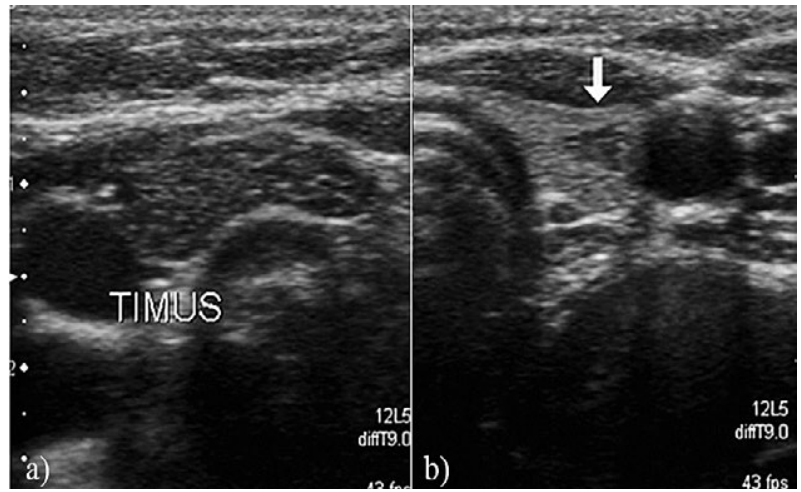

Fig 3. Thymus of the patient (a), hypoechoic lesion with weak linear echogenities and an irregular border identical in appearance to the thymus of the patient (b).

perechogenicities. All detected lesions were hypoechoic compared to surrounding thyroid. All lesions were identical in appearance to the normal thymic tissue in anterior mediastinum (fig 3).

During the follow-up there were no changes in echotexture, internal hyperechogenicities, shape or border. In an 11 year-old boy (Patient 6) who missed his 24 month appointment, the lesion had disappeared by month 29 . In an 11 year-old girl, a 5 year-old boy and a 6 year-old girl (Patients 1, 8 and 9), the lesion got slightly smaller. In a female patient with bilateral IET (Patient 13), the lesion on the right was slightly smaller by age 10 , whereas the le-

Table I. US findings of patients with intrathyroidal ectopic thymus and the follow-up results.

\begin{tabular}{|c|c|c|c|c|c|c|c|}
\hline & Sex & $\begin{array}{l}\text { Age at } \\
\text { diagnosis }\end{array}$ & $\begin{array}{l}\text { Follow-up } \\
\text { (months) }\end{array}$ & $\begin{array}{l}\text { Initial size } \\
(\mathrm{mm}) 1\end{array}$ & $\begin{array}{l}\text { Final size } \\
(\mathbf{m m})^{1}\end{array}$ & Location $^{2}$ & US characteristics $^{3}$ \\
\hline 1 & $\mathrm{~F}$ & 8 & 30 & $5 \times 3 \times 4$ & $3 \times 3 \times 3$ & R, Middle, Middle & Fusiform; Punctate and thin linear echoes \\
\hline 2 & M & 7 & 40 & $8 \times 4 \times 5$ & $6 \times 4 \times 5$ & $\mathrm{R}$, Inferior, Posterior & Fusiform; Punctate and thin linear echoes \\
\hline 3 & $\mathrm{~F}$ & 12 & 29 & $15 \times 6 \times 4$ & $15 \times 6 \times 4$ & L, Inferior, Posterior & Fusiform; No internal echoes \\
\hline 4 & M & 2 & 29 & $3 \times 3$ & $4 \times 4 \times 3$ & R, Middle, Middle & Nodular; Punctate and thin linear echoes \\
\hline 5 & M & 4 & 43 & $6 \times 2.5 \times 4$ & $7 \times 2.5 \times 4$ & $\mathrm{~L}$, Inferior, Posterior & Fusiform; Punctate and thin linear echoes \\
\hline 6 & M & 4 & 78 & $15 \times 6 \times 8$ & Disappeared & $\mathrm{L}$, Inferior, Posterior & Fusiform; Punctate and thin linear echoes \\
\hline 7 & M & 2 & 30 & $5 \times 2 \times 4$ & $4 \times 1 \times 4$ & R, Middle-lower, Posterior & Nodular; Punctate and thin linear echoes \\
\hline $8^{4}$ & M & 3 & 33 & $10 \times 6 \times 7$ & $9 \times 4 \times 7$ & $\mathrm{R}$, Inferior, Posterior & Fusiform; Punctate and thin linear echoes \\
\hline 9 & $\mathrm{~F}$ & 4 & 30 & $8 \times 6 \times 6$ & $7 \times 4.5 \times 3$ & $\mathrm{R}$, Inferior, Posterior & Fusiform; No internal echoes \\
\hline 10 & M & 9 & 29 & $4 \times 7$ & $5 \times 4 \times 10$ & L, Middle-lower, Posterior & Fusiform; Punctate and thin linear echoes \\
\hline $11^{5}$ & M & 5 & 0 & $6 \times 2 \times 5$ & - & $\mathrm{R}$, Inferior, Posterior & Fusiform; Punctate and thin linear echoes \\
\hline $12^{6}$ & $\mathrm{~F}$ & 5 & 0 & $5 \times 6.5$ & - & L, Inferior, Middle & Fusiform; Punctate and thin linear echoes \\
\hline 13 & $\mathrm{~F}$ & 4 & 66 & $\begin{array}{l}11 \times 8 \times 7(\mathrm{R}) \\
3 \times 5(\mathrm{~L})\end{array}$ & $\begin{array}{l}9 \times 6 \times 6(\mathrm{R}) \\
5 \times 3 \times 5(\mathrm{~L})\end{array}$ & $\begin{array}{l}\text { Bilateral, Inferior, Pos- } \\
\text { terior }\end{array}$ & Fusiform; Punctate and thin linear echoes \\
\hline $14^{6}$ & $\mathrm{~F}$ & 9 & 0 & $\begin{array}{l}10 \times 4 \times 5(\mathrm{R}) \\
11 \times 5 \times 7(\mathrm{~L})\end{array}$ & - & Bilateral, Inferior, Middle & Nodular, Punctate and thin linear echoes \\
\hline
\end{tabular}

${ }^{1}$ Longitudinal x AP x transverse; if only 2 dimensions are given transverse x AP; ${ }^{2}$ Respectively; side, craniocaudal location as described in methods, anteroposterior location as described in methods; ${ }^{3}$ All lesions were hypoechoic compared to surrounding thyroid, had well defined borders and were identical in sonographic appearance to normal thymus of the patient; ${ }^{4}$ Underwent fine-needle aspiration; cytologic diagnosis was IET. The echogenicity of the lesion increased during follow-up; ${ }^{3}$ Underwent hemithyroidectomy; pathologic diagnosis was IET; ${ }^{6}$ Lost to follow-up. R- right, L-left. 


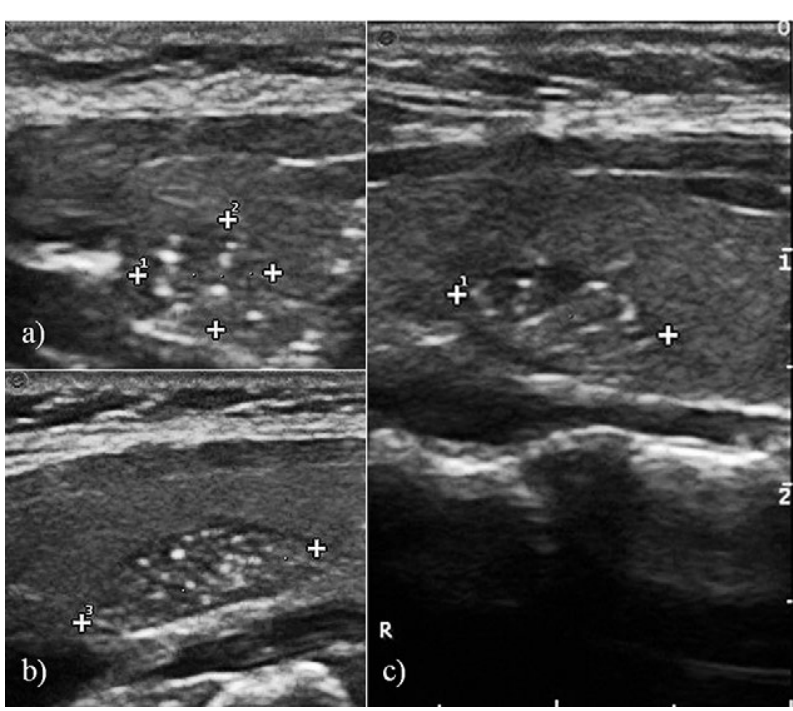

Fig 4. a) and b) fusiform hypoechoic lesion with punctate and thin linear internal echoes in a 3 year-old patient (Patient 8). Due to concern over malignancy, the patient underwent FNA and the diagnosis of IET was confirmed; c) Follow-up image at month 33 , where the image is slightly more echogenic despite being stable in size.

sion on the left was stable in size. In a 10 year-old boy (Patient 10), IET slightly grew in size from $7 \times 4 \mathrm{~mm}$ to $10 \times 4$ $\mathrm{mm}$ by month 12 , but was then stable. In all other patients, the lesions were stable in size. In one patient (Patient 8), the lesion was stable in size but its echogenicity increased and its borders were less distinct in the final evaluation at month 33. The findings are summarized in Table I. There was no associated cervical lymphadenopathy.

One of the patients underwent thyroidectomy and one had FNA due to concerns over possible thyroid malignancy (fig 4). In both cases, the diagnosis of IET was confirmed pathologically.

\section{Discussions}

Thymus is the central lymphoid organ of infancy and is responsible for the formation of mature T lymphocytes [8]. Thymus arises bilaterally from the $3^{\text {rd }}$, and to a lesser extent $4^{\text {th }}$ branchial pouches starting from the fifth or sixth gestational week [4,9]. During the seventh week thymic primordia located in the pharynx start their descent medially and caudally. In the eighth week, thymic tissue reaches anterior mediastinum and left and right primordia fuse at their lower poles. At this point, thymus consists only of epithelial cells, but from week 9 to 1416 , lymphoid cells from the liver and bone marrow migrate to the thymus, which then differentiates into cortex and medulla [9]. Thymus may fail to descend, or even when it descends to anterior mediastinum, there may be thymic remnants at any point along its path $[4,8]$. In such cases, ectopic cervical thymic tissue can be encountered from the angle of mandible to the manubrium [8]. The level of thyroid is the most common site for ectopic cervical thymus, which may be due to the close relationship of the descent of the two organs $[4,10]$.

Because of the close relationship of the descent of thyroid and thymus in prenatal life, it might be expected that ectopic thymus can also be located inside the thyroid gland. IET is an old entity, first described in 1937 by Gilmour. He reported a fetus with the thymus buried within thyroid and an instance of thymus in a similar location in an infant [11]. Parathyroid glands also have a similar embriyologic origin, and in fact there have been rare cases of IET accompanying or surrounding intrathyroidal parathyroid gland $[12,13]$. In 1976, Carpenter et al reported 9 cases with thymus inclusions in thyroid glands of 350 children $(2.6 \%)$ [14]. More recent studies report IET in $0.4-3.1 \%$ of children [5,7]. The study by Avula et al had 52 incidental thyroid pathologies detected by US, of which $9(17.3 \%)$ were ectopic thymus [5]. It should be noted that all these studies were undertaken with children referred for neck or thyroid US because of medical indications and thus do not necessarily reflect the prevalence in the general population. A study in Japan reported $0.99 \%$ incidence of IET in the general pediatric population, whereas a study in a different area of Japan reported IET in $1.95 \%$ of children $[15,16]$.

In our study, we evaluated 180 children, where we found $7(3.9 \%)$ cases consistent with intrathyroidal ectopic thymus. The incidence we found was slightly higher than reported by the literature, but is still in accordance with some of the more recent literature [5]. This may be because of more widespread use of US and greater awareness of this entity resulting in cases that would be misdiagnosed as thyroid nodules in the past.

The overwhelming majority of IET were located posteriorly in the lower thirds of the gland, even though there were some in the middle thirds. Of special note is the fact that none of the nodules were located anteriorly or superiorly. This is similar to other published results $[7,9,17]$. However, in the study by Yildiz et al the authors report all but one IET in the mid portion of the gland [4]. We attribute this contradiction to the fact that, Yildiz et al considered only cases totally enclosed within the thyroid gland whereas in our study (as well as most of the literature), peripheral lesions are included as well.

The echogenicity and internal structure of the nodule are also important for differential diagnosis. In our experience, IET is typically fusiform, with well-defined but slightly irregular borders. They are invariably hypoechoic, and may in fact be more hypoechoic than the 
surrounding strap muscles (defined in the more recent literature of thyroid nodules as very hypoechoic). They usually have internal echoes, careful scrutiny of which is essential to differentiate from microcalcifications. The echogenicities in IET correspond to either fat against lymphoid tissue or connective tissue septae and vessels in thymic tissue as seen with US en face (in which case they are seen as punctate echogenicities) or from the side (in which case they are seen as linear echogenicities) $[7,18]$. Since they are caused by the septae and vessels or fat-lymphoid tissue interface, they form continuous structures connected to each other in branching or reticulate patterns rather than discrete punctate echoes. Another important point is that in all our cases, IET had US appearance identical to the normal thymus of the patient.

As can be seen from our description of a typical IET, the nodules share much in common with worrying thyroid nodules. The most important clues for differential diagnosis would be typical location posteriorly in middle-lower thirds of the gland and fusiform shape in the craniocaudal direction. Thyroid nodules, as the name implies, are typically nodular in shape, therefore fusiform appearance is an important sign that one is looking at an IET rather than a nodule.

The thymus has the greatest relative size at birth, and continues to grow until puberty, when it reaches its greatest absolute size [9]. Since IET is essentially normal thymic tissue in an abnormal location, it would be logical to expect it to follow the same growth trend. In the study by Fukushima et al, the authors reported that IET incidence was inversely correlated with age [15]. However, there has also been a case of IET reported in a 29 year-old woman, which, to our knowledge is the only case reported in an adult [12]. In our study, we only had one case where the lesion increased in size (a boy 10 years-old at the time) in month 12 , but was then stable. The oldest patient at time of diagnosis was 12 years-old, which might implicate regression and disappearance of the lesion with puberty, corresponding to the involution of thymus. During follow-up, an 11 year-old girl had her lesion decrease in size and in a 12 year-old boy the lesion disappeared further supporting this hypothesis. However, the lesion got smaller in a 5 year-old boy and a 6 yearold girl as well. In one patient with FNA proven IET, the lesion increased in echogenicity during follow-up and at month 33 , the borders of the lesion were less welldefined. Such an increase in echogenicity and borders getting less well-defined have been described during the involution phase [6]. However, our patient was a 5 yearold, which would be too early for pubertal regression of thymic tissue; therefore, it seems such changes might be encountered earlier than previously reported. Another point to note would be that ectopic thymic tissue has been reported to enlarge with infection or vaccination, which resolves with antibiotic or steroid treatment [9]. To our knowledge, there are no reported cases of such an enlargement in an IET and we did not encounter such a case in our patients.

Thyroid nodules are more likely to be malignant in children compared to adults [19]. Therefore, misdiagnosis of a nodule with microcalcifications as IET might have unfortunate results. It is essential to properly recognize an IET, not only because of the need to differentiate it from thyroid malignancy, as described above, but also because not recognizing it means the child undergoing an unnecessary fine needle aspiration (FNA) or even hemithyroidectomy. Sonographic differential diagnosis also includes parathyroid adenomas and nodular type of Hashimoto thyroiditis [4]. Further complicating the matter is that, since the aspirate from IET would contain lymphoid cells, the cytologist might evaluate it as Hashimoto's thyroiditis or even thyroid lymphoma $[3,20,21]$.

There is no universally accepted approach for management of these lesions. It has been reported that $6 \%$ of ectopic cervical thymus can cause dysphagia, dyspnea or stridor; however, to our knowledge no such symptoms have been reported in cases with IET [8]. There have been rare cases of thymoma, thymic carcinoma and lymphocyte-predominant lymphoma arising from the ectopic thymic tissue $[10,22,23]$. Ectopic thymus can also undergo thymic hyperplasia and may potentially play a role in myasthenia gravis $[10,24]$. We think that a yearly US follow-up of the patients until regression of the lesion would be a reasonable management strategy.

Our study had some limitations. First of all, owing to the relative rarity of IET, we had a relatively small number of cases, which was further compounded by the loss of some patients to follow-up. Other limitations of the study are that although the diagnosis was considered certain by typical features and follow-up findings, some cases may have been misdiagnosed. Since biopsy is not indicated in these cases, inevitably the final diagnosis was not verified by pathology. Since none of the children had risk factors such as radiotherapy or family history of MEN syndromes, we planned follow-up and performing FNA or additional lab tests such as calcitonin, only in cases where there were suspicious findings in US. There are studies in the literature that diagnose IET without calcitonin levels $[4,7,15]$. However, determining calcitonin levels might have been useful to rule out medullary thyroid carcinoma. Finally, since the lesion is expected to disappear following puberty, we were not yet able to observe the regression in all our patients. The patients are still being followed-up to address this issue. 
We believe that IET in children are more common than thought. A typical lesion is located posteriorly in middle or lower thirds of the thyroid; is hypoechoic, with a complex pattern of punctate and linear internal echoes, fusiform shape and well defined but slightly irregular borders. Its growth reflects that of normal thymus and regresses following puberty. During follow-up there might be an increase in echogenicity. Awareness of this entity is important not to misdiagnose them as possibly malignant nodules and to prevent unnecessary interventions.

\section{Conclusions}

Ectopic thymus should be kept in mind when a hypoechoic nodule with punctate and linear echoes, especially in the posterior-lower thyroid, is seen in a child.

\section{Conflict of interest: none}

\section{References}

1. Babcock DS. Thyroid disease in the pediatric patient: emphasizing imaging with sonography. Pediatr Radiol 2006;36:299-308.

2. Tracy ET, Roman SA. Current management of pediatric thyroid disease and differentiated thyroid cancer. Curr Opin Oncol 2016;28:37-42.

3. Hernandez-Cassis C, Poniecka A, Vogel CK, McKenzie JM. A six-year-old boy with a suspicious thyroid nodule: intrathyroidal thymic tissue. Thyroid 2008;18:377-380.

4. Yildiz AE, Ceyhan K, Siklar Z, et al. Intrathyroidal Ectopic Thymus in Children: Retrospective Analysis of Grayscale and Doppler Sonographic Features. J Ultrasound Med 2015;34:1651-1656.

5. Avula S, Daneman A, Navarro OM, Moineddin R, Urbach $S$, Daneman D. Incidental thyroid abnormalities identified on neck US for non-thyroid disorders. Pediatr Radiol 2010;40:1774-1780.

6. Segni M, di Nardo R, Pucarelli I, Biffoni M. Ectopic intrathyroidal thymus in children: a long-term follow-up study. Horm Res Paediatr 2011;75:258-263.

7. Kim HG, Kim MJ, Lee MJ. Sonographic appearance of intrathyroid ectopic thymus in children. J Clin Ultrasound 2012;40:266-271.

8. Park JJ, Kim JW, Kim JP, Ahn SK, Jeong JH, Jeon SY. Two cases of ectopic cervical thymus: case reports and a review of the literature. Auris Nasus Larynx 2006;33:101-105.

9. Megremis S, Stiakaki E, Tritou I, Bonapart IE, Tsilimigaki A. Ectopic intrathyroidal thymus misdiagnosed as a thyroid nodule: sonographic appearance. J Clin Ultrasound 2008;36:443-447.
10. Wu SL, Gupta D, Connelly J. Adult ectopic thymus adjacent to thyroid and parathyroid. Arch Pathol Lab Med 2001; 125:842-843.

11. Gilmour JR. The embryology of the parathyroid glands, the thymus and certain associated rudiments. J Pathol 1937;45:507-522.

12. Kim A, Kang SH, Bae YK. Ectopic intrathyroidal thymus accompanied by intrathyroidal parathyroid as a cause of a solitary thyroid nodule in adult. Int J Clin Exp Pathol 2014;7:6375-6378.

13. Lignitz S, Musholt TJ, Kreft A, Engel R, Brzezinska R, Pohlenz J. Intrathyroidal thymic tissue surrounding an intrathyroidal parathyroid gland, the cause of a solitary thyroid nodule in a 6-year-old boy. Thyroid 2008;18:11251130 .

14. Carpenter GR, Emery JL. Inclusions in the human thyroid. J Anat 1976;122:77-89.

15. Fukushima T, Suzuki S, Ohira T, et al; Thyroid Examination Unit of the Radiation Medical Center for the Fukushima Health Management Survey. Prevalence of ectopic intrathyroidal thymus in Japan: the Fukushima health management survey. Thyroid 2015;25:534-537.

16. Hayashida N, Imaizumi M, Shimura $H$, et al. Thyroid ultrasound findings in children from three Japanese prefectures: Aomori, Yamanashi and Nagasaki. PLoS ONE 2013:8:e83220.

17. Park SH, Ryu CW, Kim GY, Shim KS. Intrathyroidal thymic tissue mimicking a malignant thyroid nodule in a 4-yearold child. Ultrasonography 2014;33:71-73.

18. Han BK, Suh YL, Yoon HK. Thymic ultrasound. I. Intrathymic anatomy in infants. Pediatr Radiol 2001;31:474479.

19. Francis GL, Waguespack SG, Bauer AJ, et al; American Thyroid Association Guidelines Task Force. Management Guidelines for Children with Thyroid Nodules and Differentiated Thyroid Cancer. Thyroid 2015;25:716-759.

20. Thakur A, Sebag F, Micco CD, Slotema E, Henry FJ. Ectopic cervical thymoma mimicking as papillary thyroid carcinoma: a diagnostic dilemma. Indian J Pathol Microbiol 2010;53:305-307.

21. Courcoutsakis N, Patronas N, Filie AC, Carney JA, Moraitis A, Stratakis CA. Ectopic thymus presenting as a thyroid nodule in a patient with the Carney complex. Thyroid 2009;19:293-296.

22. Büyükyavuz I, Otçu S, Karnak I, Akçören Z, Senocak ME. Ectopic thymic tissue as a rare and confusing entity. Eur J Pediatr Surg 2002;12:327-329.

23. Gimm O, Krause U, Wessel H, Finke R, Dralle H. Ectopic intrathyroidal thymus diagnosed as a solid thyroid lesion: case report and review of the literature. J Pediatr Surg 1997;32:1241-1243.

24. Ambrogi V, Mineo TC. Active ectopic thymus predicts poor outcome after thymectomy in class III myasthenia gravis. J Thorac Cardiovasc Surg 2012;143:601-606. 